\title{
Red pitaya (Hylocereus costaricensis) peel as a source of valuable molecules: Extraction optimization to recover natural colouring agents
}

\author{
Custódio Lobo Roriz $^{\text {a,b }}$, Sandrina A. Heleno ${ }^{\text {a }}$, Maria José Alves ${ }^{\text {a }}$, M. Beatriz P.P. Oliveira ${ }^{c}$, \\ José Pinela $^{\mathrm{a}}$, Maria Inês Dias ${ }^{\mathrm{a}}$, Ricardo C. Calhelha ${ }^{\mathrm{a}}$, Patricia Morales ${ }^{\mathrm{b}}$, Isabel C.F.R. Ferreira ${ }^{\mathrm{a}}$, \\ Lillian Barros ${ }^{\text {a, }}$ \\ ${ }^{a}$ Centro de Investigação de Montanha (CIMO), Instituto Politécnico de Bragança, Campus de Santa Apolónia, 5300-253 Bragança, Portugal \\ ${ }^{\mathrm{b}}$ Dpto. Nutrición y Ciencia de los Alimentos, Facultad de Farmacia. Universidad Complutense de Madrid (UCM), Pza Ramón y Cajal, s/n. E-28040, Madrid, Spain \\ ${ }^{\mathrm{c}}$ REQUIMTE/LAQV, Department of Chemical Sciences, Faculty of Pharmacy, University of Porto, R. Jorge Viterbo Ferreira, 228 $4050-313$ Porto, Portugal
}

\section{A R T I C L E I N F O}

\section{Keywords:}

Hylocereus costaricensis

Bioactive compounds

Betacyanins

Natural colorants

Ultrasound-assisted extraction

Process optimization

\begin{abstract}
A B S T R A C T
Hylocereus costaricensis peel contains large amounts of betacyanins and can be exploited as a source of natural colorants. This work aimed the chemical characterization and evaluation of bioactive properties of this byproduct and the optimization of the ultrasound-assisted extraction (UAE) of betacyanins using the response surface methodology (RSM). Oxalic and malic acids and traces of fumaric acid were detected, as well as the four tocopherol isoforms, predominantly $\gamma$-tocopherol. Four betacyanins were identified and used as response criteria for UAE optimization, namely phyllocactin, isobetanin, isophyllocactin, and betanin. Sample processing at $487 \mathrm{~W}$ for $38 \mathrm{~min}$ result in the maximum betacyanin content $(36 \pm 1 \mathrm{mg} / \mathrm{g} \mathrm{dw})$. The peel extract inhibit the oxidative haemolysis, with $\mathrm{IC}_{50}$ values of 255 and $381 \mu \mathrm{g} / \mathrm{mL}$ for $\Delta t$ of 60 and $120 \mathrm{~min}$, respectively, and the growth of pathogenic bacteria, with minimum inhibitory concentrations ranging from 5 to $20 \mathrm{mg} / \mathrm{mL}$. Furthermore, no toxicity was observed for normal cells.
\end{abstract}

\section{Introduction}

The increasing demand for products with less or non-artificial additives has prompted the exploitation of natural matrices under exhaustive research by the scientific community. This investigation has the main objective of providing the different industries with natural biomolecules, increasing their economy through the development of products with high acceptability by the final consumers (Lira et al., 2020; Martins, Roriz, Morales, Barros, \& Ferreira, 2016; Volpentesta, Felicetti, \& Ammirato, 2017). The particular case of natural colourants has been one of the main challenges due to their low stability after incorporation into foods or cosmetics. This problematic has led to the research and development of stabilization techniques that can ensure their effective applicability that is the replacement of artificial colourants (Roriz et al., 2020).

Among the natural colourants, there are interesting matrices from which it is possible to obtain different colouring compounds. This is the case of a peculiar and visually striking fruit, the pitaya (Hylocereus spp.), commonly known as dragon fruit, comprising different species of the
Cactaceae family, indigenous to the centre and south of the American continent (Esquivel, Stintzing, \& Carle, 2007). Despite being native to these regions, their production and exploitation is already widespread and adapted to different areas of the globe (Rebeca, Boyce, \& Chandran, 2010). There are several species of this fruit, however among the most cultivated/exploited species around the world it is possible to find: Hylocereus undatus, Hylocereus costaricensis and Hylocereus megalanthus. The main differences of these fruits are related to the colour presented by the peel and pulp; thus i) $H$. undatus, or white flesh pitaya, presents with pink peel and white pulp, ii) $H$ constaricensis or red flesh pitaya, with reddish pink peel and red pulp, and iii) $H$. megalanthus or yellow pitaya, with yellow peel and white pulp. Numerous biological activities are attributed to these fruits, such as antioxidant, anticancer, hypocholesterolemic, and antibacterial properties along with prebiotic effects (Singh, 1997), that may be associated with high levels of different nutrients and bioactive compounds (Tenore, Novellino, \& Basile, 2012). The colour displayed by these fruits is due to the presence of specific compounds named betalains (Martins, Roriz, Morales, Barros, \& Ferreira, 2017), that include two subgroups: betaxanthins, in the yellow

\footnotetext{
* Corresponding author.

E-mail address: lillian@ipb.pt (L. Barros).
} 
colour range, and betacyanins, in the purple range, both present in different fruits of these species (Lee et al., 2014). Betalains are of great interest at an industrial level, as they can be used as natural, safer, and healthier alternatives to artificial colourants. Therefore, it becomes interesting to explore these fruits, as they are extremely appreciated, and can be used for various purposes. Besides being consumed in natura, their pulp is commonly used to prepare juices, smoothies, ice creams, jams, pitayas are also commonly applied in skin care formulations (Hua et al., 2018). These uses result in excessive leftover of fruit peels, considered as bio-residues, but extremely rich in betacyanin compounds. About $35 \%$ of the total weight of the fruit relates to its peel; however, it is currently treated as waste and is simply discarded during industrial processing. Interestingly, there are several studies that report that these discarded peels present promising bioactive capacities due to the presence of these betacyanins, (Faridah, Holinesti, \& Syukri, 2015), that at the same time present an intense colour, being a huge and unexplored raw material. Bearing this in mind, and being in line with the global politics, it is necessary to give new life to underutilized resources, namely bio-residues with no valuable destination, privileging circular economy and sustainability, promoting social economic development, and reducing environmental damage (Bakar, Ee, Muhammad, Hashim, \& Adzahan, 2013). Therefore, in this work, the peel of red pitaya (Hylocereus costaricensis (F.A.C. Weber) Britton \& Rose) was explored as a novel alternative source of betacyanins. The ultrasound-assisted extraction (UAE) technique was applied and the extraction parameters were optimized using the response surface methodology (RSM) in order to obtain a betacyanin-rich extract with colouring capacity. Moreover, and given the lack of scientific information regarding the chemical composition of this fruit, other important compounds such as organic acids and tocopherols were identified in this by-product to boost the exploitation of this fruit peels as sources of bioactive molecules. Finally, the bioactive potential of the peel extract was also evaluated for its antioxidant, antimicrobial and hepatotoxic properties.

\section{Material and methods}

\subsection{Plant material}

Peel samples of Hylocereus costaricensis were kindly provided by Ángel Ferrero, from Pitayas de Galicia, a research project on the acclimatization and cultivation of this fruit in the region. The botanical identification of the species was made by the botanical expert responsible for the herbarium of Escola Superior Agrária (BRESA) from Instituto Politécnico de Bragança (Trás-os-Montes, Portugal). Subsequently, the peels were frozen, lyophilized (FreeZone 4.5, Labconco, Kansas City, MO, USA), and finally grounded at 20 mesh, and kept in a container protected from light and humidity until further analysis.

\subsection{Plant and extract colour measurement}

A colorimeter (model CR-400, Konica Minolta Sensig Inc., Tokyo, Japan) calibrated against a standard white tile, equipped with an illuminant $C$ and an $8 \mathrm{~mm}$ aperture, was used to measure the colour of the dried pitaya peel powder and its extract, recovered accordingly to the description made in section 2.3.3.. A Spectra Magic Nx software (version CM-S100W 2.03.0006) was used to record the CIE $L^{*}$ (lightness), $a^{*}$ (greenness-redness), and $b^{*}$ (blueness-yellowness) colour space values.

\subsection{Chemical composition analysis}

\subsubsection{Organic acids}

Organic acids analysis was performed in a Shimadzu 20A series (Shimadzu Corporation, Kyoto, Japan), determined by Ultra-Fast Liquid Chromatography (UFLC), following the methodology previously described by Pereira et al. (2013). A SphereClone (Phenomenex, Torrance, CA, USA) reverse phase C18 column (250 $\mathrm{mm} \times 4.6 \mathrm{~mm}, 5 \mu \mathrm{m})$ thermostated at $35{ }^{\circ} \mathrm{C}$ was used to achieve the separation. Sulphuric acid (3.6 mM, acquired at Fisher Scientific Lisbon, Portugal) at $0.8 \mathrm{~mL} / \mathrm{min}$ flow rate was used to perform the elution. The detection was carried out by a photodiode array detector (PDA) at $215 \mathrm{~nm}$ as preferred wavelength. Organic acids peaks of calibration curves obtained from commercial standards (acquired from Sigma St Louis, Missouri, USA) were used to quantify the detected compounds. Results were expressed in $\mathrm{mg}$ per $g$ of plant dry weight (dw).

\subsubsection{Tocopherols}

The HPLC methodology previously described by Barros et al. (2013) was followed for tocopherols determination, in a High performance liquid chromatography (HPLC) system (Knauer, Smartline system 1000, Berlin, Germany) coupled to a fluorescence detector (FP-2020; Jasco, Easton, USA) programmed at $290 \mathrm{~nm}$ for excitation and at $330 \mathrm{~nm}$ for emission. Hexane:ethyl acetate (70:30, v/v, hexane and ethyl acetate HPLC-grade, Lab-Scan, Lisbon, Portugal) composed the mobile phase mixture, and the chromatographic separation was achieved in a Polyamide II column $(250 \times 4.6 \mathrm{~mm}, 5 \mu \mathrm{m}$; YMC, Kyoto, Japan). The quantification was performed by the internal standard (tocol, Matreya, Pleasant Gap, PA, USA) method. The results were recorded and processed using Clarity 2.4 software (DataApex, Prague, Czech Republic) and express in $\mathrm{mg}$ per $\mathrm{g}$ of plant $\mathrm{dw}$.

\subsubsection{Betacyanins}

The red pitaya peel extract was obtained by UAE at $500 \mathrm{~W}$ for 22 min, using a mixture of $\mathrm{H}_{2} \mathrm{O}: \mathrm{EtOH}(90: 10, v / v)$ as extraction solvent and a solid/liquid ratio of $5 \mathrm{~g} / \mathrm{L}$. Afterwards, the EtOH was removed under reduced pressure and the remaining water was lyophilized (FreeZone 4.5, Labconco, Kansas City, MO, USA). The extracts were analysed for its bioactive properties in vitro.

The extract at a concentration of $5 \mathrm{mg} / \mathrm{mL}$ in a solution of ethanol water (10:90 v:v) were analysed for their betalain content using a Dionex Ultimate 3000 UPLC instrument (Thermo Scientific, San Jose, CA, USA), coupled to a diode-array detector (DAD) (using the preferred wavelength of $530 \mathrm{~nm}$ ) and an automatic thermostatic column compartment (with a Waters Spherisorb S3 ODS-2 C18, $3 \mu \mathrm{m}, 4.6 \mathrm{~mm} \times 150 \mathrm{~mm}$, Waters, Milford, MA, USA - column) operating at $35{ }^{\circ} \mathrm{C}$ (Celsius degrees), and, finally, in line with a mass detector Linear Ion Trap LTQ XL mass spectrometer, equipped with an ESI source, Thermo Finnigan, San Jose, CA, USA). The chromatographic and mass spectrometer conditions were performed according to the previously described by Roriz et al. (2018). The Xcalibur software (Thermo Finnigan, San Jose, CA, USA) was used to obtain and process the chromatographic data, after which the detected betacyanins were identified based on their UV-Vis and mass spectrum and further quantified using the calibration curve for Gomphrenin III $\left(y=14670 x-19725, R^{2}=0.9997\right)$. The results were expressed in $\mathrm{mg}$ per $\mathrm{g}$ of extract.

\subsection{Bioactivity evaluation}

The red pitaya peel extract obtained as described in section 2.3.3. was used for evaluation of the bioactive properties described below.

\subsubsection{Antihaemolytic activity}

The oxidative haemolysis inhibition assay (OxHLIA) was applied to assess the antioxidant capacity of the extract, following the procedure described by Mandim et al. (2019). Briefly, an erythocyte solution (2.8\%, $v / v$, in phosphate-buffered saline (PBS); $200 \mu \mathrm{L}$ ) was mixed with $400 \mu \mathrm{L}$ of either extract solution $(0.125-4 \mathrm{mg} / \mathrm{mL}$ in PBS), PBS (negative control), water (to achieved complete haemolysis), or Trolox $(3.125-100 \mu \mathrm{g} / \mathrm{mL})$. After $10 \mathrm{~min}$ pre-incubation at $32{ }^{\circ} \mathrm{C}$ with shaking, $2^{\prime}$-azobis(2-amidinopropane) dihydrochloride (AAPH) $(200 \mu \mathrm{L}, 160 \mathrm{mM}$ in PBS (from Sigma-Aldrich) was added and the optical density $(690 \mathrm{~nm}$ ) was measured every $\sim 10 \mathrm{~min}$ in a microplate reader (Bio-Tek Instruments, ELX800) until complete haemolyses. The results were 
expressed as half maximal inhibitory concentration $\left(\mathrm{IC}_{50}\right)$ values $(\mu \mathrm{g} /$ $\mathrm{mL}$ ) for $\Delta t$ of 60 and $120 \mathrm{~min}$.

\subsubsection{Antibacterial activity}

Clinical isolates of patients from hospital units in North-eastern Portugal (Centro Hospitalar de Trás-os-Montes e Alto Douro), consisting in different bacteria were used to assess the antimicrobial activity of the obtained extract. Five Gram-negative bacteria (Escherichia coli, Klebsiella pneumoniae, Morganella morganii, Pseudomonas aeruginosa and Proteus mirabilis) and three Gram-positive bacteria (methicillin-resistant Staphylococcus aureus (MRSA), Listeria monocytogenes and Enterococcus faecalis) were tested. The methodology described by Pires et al. (2018) with some modifications, namely the microdilution assay and the rapid $p$-iodonitrotetrazolium chloride (INT; Panreac Applichem, Barcelona, Spain) colorimetric assay were performed. One positive control was prepared with bacteria and Mueller-Hinton broth (MHB; Biolab, Budapest, Hungary); and negative controls were also prepared, one with MHB or tryptic soy broth (TSB; Biolab, Budapest, Hungary), one with the extract only, and the last one with medium and antibiotic (vancomycin, imipenem, and ampicillin) for each inoculum. The results were presented as minimum inhibitory concentrations (MICs, $\mathrm{mg} / \mathrm{mL}$ ), i.e., the lowest extract concentration that inhibits the visible bacterial growth, and minimum bactericidal concentrations ( $\mathrm{MBCs}, \mathrm{mg} / \mathrm{mL}$ ), i.e., the lowest extract concentration required to kill a particular bacterium.

\subsubsection{Hepatotoxic activity}

The extract toxicity to normal cells (porcine liver primary culture PLP2) was tested using the sulphorrodamine B assay previously described by Guimarães et al. (2013). The range of concentration in which the extract was tested range from 400 to $1.56 \mu \mathrm{g} / \mathrm{mL}$ and allowed determining the concentration providing $50 \%$ of cell growth inhibition $\left(\mathrm{GI}_{50}, \mu \mathrm{g} / \mathrm{mL}\right)$, using ellipticine as a positive control.

\subsection{Experimental design for extraction process optimization}

A central composite design (CCD) combining five-level of the independent variables $X_{1}$ (time, $t, 1-50 \mathrm{~min}$ ) and $X_{2}$ (ultrasonic power, $P$, $5-500 \mathrm{~W}$ ) was implemented to optimize the extraction of betacyanins from pitaya peel using RSM (Table S1 in Supplementary material). The Design-Expert software, Version 11 (Stat-Ease, Inc., Minneapolis, USA) was used to generate the 18 experimental points of the CCD design by entering the factor ranges in terms of alphas $(\alpha=1.19)$. The extractions were performed as described in section 2.4, keeping the temperature and the solid/liquid ratio constant.

\subsection{Extraction process optimization by response surface methodology}

The residue (or crude extract) and the contents of isobetanin, phyllocactin, isophyllocactin, and total betacyanins (sum of the betanin, isobetanin, phyllocactin, and isophyllocactin levels) were the dependent (or response) variables used in the extraction process optimization. The response surface models were fitted by means of least squares calculation using the following second-order polynomial equation:

$Y=b_{0}+\sum_{i=1}^{n} b_{i} X_{i}+\sum_{i=1}^{n-1} \sum_{j=2}^{n} b_{i j} X_{i} X_{j}+\sum_{i=1}^{n} b_{i i} X_{i}^{2}$

where $Y$ is the dependent variable to be modelled, $X_{\mathrm{i}}$ and $X_{\mathrm{j}}$ define the independent variables, $b_{0}$ is the constant coefficient, $b_{\mathrm{i}}$ is the coefficient of the linear effect, $b_{\mathrm{ij}}$ is the coefficient of the interaction effect, $b_{\mathrm{ii}}$ is the coefficient of the quadratic effect, and $n$ is the number of variables.

Fitting procedures, coefficient estimates, and statistical analysis were performed using Design-Expert software. Briefly, the analyses of variance (ANOVA) was used to assess the significance of the model generated and of all the terms that make up the model, as well as the lack-of- fit. Only the statistically significant terms $(p<0.05)$ were used in the construction of the theoretical models. Coefficient of determination $\left(\mathrm{R}^{2}\right)$, adjusted coefficient of determination $\left(\mathrm{R}^{2}\right.$ adj), and adequate precision, were used to estimate the adequacy of the polynomial equation to the response (Albuquerque, Pinela, Barros, Oliveira, \& Ferreira, 2020). The lack-of-fit measures the quality of the model's fit to the experimental data and should be non-significant $(p>0.05)$.

\subsection{Statistical analysis}

The results were displayed as mean \pm standard deviation (with the exception of antibacterial activity). Regarding the colour and antioxidant activity, the SPSS Statistics Software (IBM SPSS Statistics for Windows, Version 22.0. Armonk, NY: IBM Corp.) was applied to assess significant differences among two samples by applying a two-tailed paired Student's $t$-test (significance of 0.001). All the assays were performed in triplicate.

\section{Results and discussion}

\subsection{Colour of red pitaya peel and its extract}

Table 1 shows the results of the colour parameters $L^{*}$ (lightness), $a^{*}$ (redness), and $b^{*}$ (yellowness) measured in the powdered red pitaya peel sample and its dry extract. The colour of the extract was significantly ( $p$ value $<0.001$ ) more intense, as it contains higher concentrations of colouring compounds, namely betacyanins. It was possible to verify that the values of $L^{*}$ were lower in the obtained extract, but, on the other hand, the extract presents higher $a^{*}$ and $b^{*}$ values. In this way, it can be concluded that the compounds responsible for the colour were successfully extracted using UAE.

\subsection{Organic acids and tocopherols composition of red pitaya peel}

The pitaya is an extremely appealing fruit in terms of its visual appearance, largely due to the compounds responsible for its intense colour, but little or nothing exists in the literature regarding the other compounds present in the pulp and peel of this matrix. Regarding the chemical composition of the fruit peel, little has yet been done and reported in the literature. Table 2 shows the profile of red pitaya peel with regards to its composition in organic acids and tocopherols. This characterization was performed not only to provide scientific information regarding these molecules' presence in pitaya, but also to highlight that these fruits can also provide bioactive benefits due to the presence of these bioactive compounds. It was possible to identify oxalic acid (1.68 $\mathrm{g} / 100 \mathrm{~g} \mathrm{dw})$ as the major compound followed by malic acid $(1.7 \mathrm{~g} / 100 \mathrm{~g}$ $\mathrm{dw}$ ), traces of fumaric acid were also detected. Naderi et al. (2010) reported the presence of citric ( $444 \pm 5.6 \mathrm{mg} / \mathrm{L})$ and ascorbic acids $(0.5 \pm$ $0.00 \mathrm{mg} / \mathrm{L}$ ) in the juice obtained from the pulp of $H$. polyrhizus, whereas Nomura et al. (2005) described the presence of large amounts of malic, and small amounts of citric and ascorbic acids in the peels of $H$. undatus. Jamilah et al. (2011) reported the presence of oxalic $(0.80 \%)$, citric $(0.08 \%)$, malic $(0.64 \%)$, succinic $(0.19 \%)$ and fumaric acids $(0.01 \%)$ on the peel of $H$. polyrhizus and claimed that the difference in the profile of organic acids in relation to other works found in the literature may be due to the characteristics of the soil of the plantation where these fruits are obtained.

Regarding tocopherols, it was possible to identify the four isoforms, with predominance of $\gamma$-tocopherol $(11.8 \mathrm{mg} / 100 \mathrm{~g} \mathrm{dw})$, followed by the isoforms $\alpha(3.10 \mathrm{mg} / 100 \mathrm{~g} \mathrm{dw}), \delta(0.84 \mathrm{mg} / 100 \mathrm{~g} \mathrm{dw})$ and $\beta(0.164 \mathrm{mg} /$ $100 \mathrm{~g} \mathrm{dw})$. In the literature, little or no information is available regarding the profile in tocopherols for red pitaya peel. The profiles already described are relative to oils from the seeds of the fruit pulp. For the oil of two species of this fruit, namely $H$. polyrhizus and $H$. undatus, Lim, et al. (2010) describes the presence of only two isoforms, with $\alpha$-tocopherol (31.9 mg/100 g seed oil and $24.0 \mathrm{mg} / 100 \mathrm{~g}$ seed oil, 
Table 1

Colour parameters of the lyophilized red pitaya peel sample and its extract, according to the CIELAB colour space and the RGB scale.

\begin{tabular}{|c|c|c|c|c|c|c|c|}
\hline & \multicolumn{3}{|l|}{ CIELAB } & \multicolumn{3}{|l|}{ RGB } & \multirow[t]{2}{*}{ Colour } \\
\hline & $L^{*}$ & $a^{*}$ & $b^{*}$ & $\mathrm{R}$ & G & B & \\
\hline Peel sample & $59.31 \pm 0.07$ & $34.61 \pm 0.04$ & $-4.08 \pm 0.01$ & 197 & 119 & 151 & \\
\hline Peel extract & $44.67 \pm 0.07$ & $39.04 \pm 0.01$ & $0.70 \pm 0.02$ & 164 & 77 & 106 & \\
\hline$p$-Value & $<0.001$ & $<0.001$ & $<0.001$ & $<0.001$ & $<0.001$ & $<0.001$ & \\
\hline
\end{tabular}

$L^{*}$ : lightness; $a^{*}$ : greenness-redness; $b^{*}$ : blueness-yellowness; R: red; G: green; and B: blue.

Table 2

Tocopherols and organic acids composition of red pitaya peel.

\begin{tabular}{ll}
\hline Organic acids & Content $(\mathrm{g} / 100 \mathrm{~g} \mathrm{dw})$ \\
\hline Oxalic acid & $1.68 \pm 0.01$ \\
Malic acid & $1.7 \pm 0.1$ \\
Fumaric acid & $\mathrm{tr}$ \\
Total & $2.65 \pm 0.03$ \\
Tocopherols & Content $(\mathrm{mg} / 100 \mathrm{~g} \mathrm{dw})$ \\
$\alpha$-Tocopherol & $3.10 \pm 0.06$ \\
$\beta$-Tocopherol & $0.16 \pm 0.02$ \\
$\gamma$-Tocopherol & $11.8 \pm 0.2$ \\
$\delta$-Tocopherol & $0.84 \pm 0.07$ \\
Total & $15.93 \pm 0.07$ \\
\hline
\end{tabular}

tr: traces.

respectively) being the major isoform in both species and $\gamma$-tocopherol as the minor one $(11.6 \mathrm{mg} / 100 \mathrm{~g}$ seed oil and $12.7 \mathrm{mg} / 100 \mathrm{~g}$ seed oil, respectively). This difference in the composition and concentration of tocopherols, when compared with those presented in this work, is justified by the fact that seeds are generally richer sources of lipophilic compounds, although the isoforms $\delta$ and $\beta$ were also identified in the peel.

\subsection{Betacyanins composition of red pitaya peel}

The tentative identification and quantification of the betacyanins detected in the red pitaya peel extract, as well as the chromatographic

Table 3

Betacyanins tentatively identified in red pitaya peel extract. The retention time (Rt), wavelengths of maximum absorption in the visible region $\left(\lambda_{\max }\right)$, mass spectral data, and betacyanins content are presented.

\begin{tabular}{|c|c|c|c|c|c|c|}
\hline Peak & $\begin{array}{l}\text { Rt } \\
(\min )\end{array}$ & $\lambda_{\max }(\mathrm{nm})$ & $\begin{array}{l}{[\mathrm{H}]^{+}(m /} \\
z)\end{array}$ & $\mathrm{MS}^{2}$ & $\begin{array}{l}\text { Tentative } \\
\text { identification }\end{array}$ & $\begin{array}{l}\text { Content } \\
\text { (mg/g } \\
\text { extract) }\end{array}$ \\
\hline 1 & 19.40 & 534 & 551 & $\begin{array}{l}551 \\
(100), \\
389(40)\end{array}$ & Betanin & $\begin{array}{l}10.1 \pm \\
0.2\end{array}$ \\
\hline 2 & 20.86 & 533 & 551 & $\begin{array}{l}551 \\
(100), \\
389(27)\end{array}$ & Isobetanin & $\begin{array}{l}11.8 \pm \\
0.6\end{array}$ \\
\hline 3 & 22.74 & 535 & 637 & $\begin{array}{l}619 \\
(12), \\
593 \\
(15), \\
551 \\
(35), \\
389 \\
(100)\end{array}$ & Phyllocactin & $\begin{array}{l}14.8 \pm \\
0.3\end{array}$ \\
\hline \multirow[t]{2}{*}{4} & 23.76 & 533 & 637 & $\begin{array}{l}619 \\
(12), \\
593 \\
(15), \\
551 \\
(35), \\
389 \\
(100)\end{array}$ & Isophyllocactin & $\begin{array}{l}11.7 \pm \\
0.2\end{array}$ \\
\hline & & & & & Total & $\begin{array}{l}48.3 \pm \\
0.8\end{array}$ \\
\hline
\end{tabular}

responses of retention times, wavelength of maximum absorption in the visible region, and mass spectral data are shown in Table 3. Four compounds were tentatively identified, namely betanin $\left([\mathrm{H}]^{+}\right.$at $\left.m / z 551\right)$, isobetanin $\left([\mathrm{H}]^{+}\right.$at $\left.m / z 551\right)$, phyllocactin $\left([\mathrm{H}]^{+}\right.$at $\left.m / z 637\right)$, and isophyllocactin $\left([\mathrm{H}]^{+}\right.$at $\left.m / z 637\right)$, considering previous studies carried out with red pitaya fruits (Cai, Xing, Sun, \& Corke, 2006; Stintzing, Schieber, \& Carle, 2002). Regarding the quantification, it was possible to verify that the major compound is the one corresponding to peak 3 , phyllocactin (14.8 mg/g extract), followed by peak 2 , isobetanin (11.8 $\mathrm{mg} / \mathrm{g}$ extract), and isophyllocactin ( $11.7 \mathrm{mg} / \mathrm{g}$ extract), and finally peak 1 , betanin $(10.1 \mathrm{mg} / \mathrm{g}$ extract). Due to the similarity of the quantified contents, all compounds were considered for the UAE optimization carried out by RSM.

\subsection{Bioactive properties of red pitaya peel extract}

Table 4 presents the results of the evaluated bioactive properties of the red pitaya peel extract. For the antihaemolytic activity assessed by the OxHLIA assay. The protection of half the erythrocyte population from the oxidative haemolysis induced by the temperature dependent free radical initiator, AAPH, was achieved at the extract concentrations of $255 \mu \mathrm{g} / \mathrm{mL}$ and $381 \mu \mathrm{g} / \mathrm{mL}$, for $\Delta t$ of 60 and $120 \mathrm{~min}$, respectively. Trolox, the tested positive control, had IC 50 values of $20.4 \mu \mathrm{g} / \mathrm{mL}$ and 44 $\mu \mathrm{g} / \mathrm{mL}$ for $\Delta t$ of 60 and $120 \mathrm{~min}$, respectively, thus showing greater efficiency in protecting the erythrocytes than the red pitaya peel extract. The greater activity of Trolox may be due to the fact that it is a pure antioxidant compound, whereas the plant extract is a complex mixture of several constituents, some of which have no biological activity or may have antagonistic effects. Furthermore, when analysing the results obtained for Trolox, it is possible to notice that the $\mathrm{IC}_{50}$ value presented for the $\Delta t$ of $120 \mathrm{~min}$ is about twice the value obtained for the $60 \mathrm{~min} \Delta t$. As expected, the extract had a similar behaviour, requiring a higher concentration to protect the erythrocyte membranes for a longer $\Delta t$. However, the extract concentration required for the $120 \mathrm{~min} \Delta t$ was only 1.5 times higher than that required for the $60 \mathrm{~min} \Delta t$ (Table 4), which indicates the antioxidant efficiency of the extract for longer periods of exposure to the haemolytic action of the free radicals generated in the system.

Although there are some reports on the bioactive properties of this species (de Mello et al., 2015; Esquivel et al., 2007; Taira, Tsuchida, Katoh, Uehara, \& Ogi, 2015; Tenore et al., 2012), the comparison of results is difficult due to the different mechanisms of action of the antioxidant assays that have been carried out. For instance, de Mello et al. (2015) evaluated the antioxidant activity of $H$. undatus peel extract using the DPPH and FRAP assays and reported results of $177.14 \mu \mathrm{mol}$ AEAC/100 $\mathrm{g}$ for DDPH and $109.29 \mu \mathrm{mol} \mathrm{AEAC/100} \mathrm{g}$ for FRAP. Tenore at al. (2012) applied the same assays to their peel and flesh samples and expressed the results in Trolox equivalents (TE). The peel fraction resulted in $805 \pm 1 \mu \mathrm{mol} \mathrm{TE} / 100 \mathrm{~g}$ fw and $478 \pm 2 \mu \mathrm{mol} \mathrm{TE} / 100 \mathrm{~g}$ fw for the DPPH and FRAP assays, respectively. For the flesh sample, $1000 \pm 1$ $\mu \mathrm{mol} \mathrm{TE} / 100 \mathrm{~g} \mathrm{fw}$ and $437 \pm 2 \mu \mathrm{mol} \mathrm{TE} / 100 \mathrm{~g}$ fw were obtained with the DPPH and FRAP assays, respectively. In another study, Taira et al. (2015) tested the antioxidant capacity of betanin, phyllocactin, and betanidin as an index of radical scavenging ability and reported $10.70 \pm$ $0.01,3.31 \pm 0.14$ and $2.83 \pm 0.01 \mathrm{~mol}-\mathrm{TE} / \mathrm{mol}$-compound for betanidin, betanin, and phyllocactin, respectively. Esquivel et al. (2007) applied 
Antihaemolytic and antibacterial activities of red pitaya peel extract and positive controls.

\begin{tabular}{|c|c|c|c|c|c|c|c|c|}
\hline & \multicolumn{2}{|c|}{ Peel extract } & \multicolumn{6}{|c|}{ Positive controls } \\
\hline \multicolumn{3}{|l|}{ Antihaemolytic activity $\left(\mathrm{IC}_{50}, \mu \mathrm{g} / \mathrm{mL}\right)$} & \multicolumn{6}{|l|}{ Trolox } \\
\hline OxHLIA, $\Delta t=60 \mathrm{~min}$ & \multicolumn{2}{|c|}{$255 \pm 6$} & \multicolumn{6}{|c|}{$20.4 \pm 0.5$} \\
\hline OxHLIA, $\Delta t=120 \mathrm{~min}$ & \multirow{2}{*}{\multicolumn{2}{|c|}{$381 \pm 8$}} & \multicolumn{6}{|l|}{$44 \pm 1$} \\
\hline \multirow[t]{2}{*}{ Antibacterial activity (MIC \& MBC, mg/mL) } & & & \multicolumn{2}{|c|}{ Ampicillin $(20$ mg/mL) } & \multicolumn{2}{|c|}{ Imipenem (1 mg/mL) } & \multicolumn{2}{|c|}{ Vancomycin $(1 \mathrm{mg} / \mathrm{mL})$} \\
\hline & MIC & MBC & MIC & MBC & MIC & MBC & MIC & MBC \\
\hline \multicolumn{9}{|l|}{ Gram-negative bacteria } \\
\hline Escherichia coli & 10 & $>20$ & $<0.15$ & $<0.15$ & $<0.0078$ & $<0.0078$ & $\mathrm{nt}$ & nt \\
\hline Klebsiella pneumoniae & 20 & $>20$ & 10 & 20 & $<0.0078$ & $<0.0078$ & nt & nt \\
\hline Morganella morganii & 10 & $>20$ & 20 & $>20$ & $<0.0078$ & $<0.0078$ & $\mathrm{nt}$ & nt \\
\hline Proteus mirabilis & $>20$ & $>20$ & $<015$ & $<0.15$ & $<0.0078$ & $<0.0078$ & $\mathrm{nt}$ & nt \\
\hline Pseudomonas aeruginosa & 20 & $>20$ & $>20$ & $>20$ & 0.5 & 1 & $\mathrm{nt}$ & nt \\
\hline \multicolumn{9}{|l|}{ Gram-positive bacteria } \\
\hline Enterococcus faecalis & 5 & $>20$ & $<0.15$ & $<0.15$ & nt & nt & $<0.0078$ & $<0.0078$ \\
\hline Listeria monocytogenes & $>20$ & $>20$ & $<0.15$ & $<0.15$ & $<0.0078$ & $<0.0078$ & nt & nt \\
\hline MRSA & 20 & $>20$ & $<0.15$ & $<0.15$ & nt & nt & 0.25 & 0.5 \\
\hline
\end{tabular}

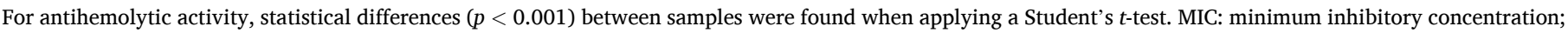
MBC: minimum bactericidal concentration; nt: not tested.

the Trolox equivalent antioxidant capacity (TEAC) assay to different Hylocereus genotypes and the results ranged from $24.5 \pm 0.8$ to $36 \pm 3$ $\mathrm{mg} / 100 \mathrm{~mL}$ of ascorbic acid equivalents.

Table 4 also shows the results of the antibacterial activity of the red pitaya peel extract, where it is possible to observe that it had activity against most of the tested microorganisms, except for the Gram-negative bacteria $P$. mirabilis and the Gram-positive bacteria L. monocytogenes. These two bacteria were not inhibited at the maximum tested concentration of $20 \mathrm{mg} / \mathrm{mL}$. The susceptibility to the extract is quite similar in both Gram-positive and negative bacteria, but for some Gram-negative bacteria the results are more appealing. For instance, the concentration of the extract needed to inhibit M. morganii was $10 \mathrm{mg} / \mathrm{mL}$, lower than the MIC value displayed by the positive control of ampicillin (20 $\mathrm{mg} / \mathrm{mL}$ ). Natural extracts displaying similar/higher antibacterial potential than the commonly used antibiotics is of great relevance since the inefficiency of antibiotics against bacterial strains is growing.

Regarding the bioactivities for these species, pulp, peel, seed, and even flower, several studies have been reported, as mentioned previously. However, for antibacterial activity, Yong et al. (2018) conducted a study on $H$. polirhyzus and the MIC values of fruits obtained from three different farms against some of the bacteria also used in the present study were around $50,000 \mu \mathrm{g} / \mathrm{mL}$. The authors also describe that the sensitivity of Gram-positive bacteria was higher than Gram-negative bacteria, possibly due to the presence of the external cell wall in Gram-negative bacteria, acting as a selective permeation barrier. Tenore et al. (2012), assessed the antibacterial activity of peels, pulp (flesh), and fractions rich in betacyanins, flavonoids and phenolic acids from both peels and pulp of $H$. polirhyzus fruits, against two yeasts, four moulds and thirteen bacteria species selected as representative of the classes of Gram-positive and Gram-negative. The MIC values obtained by these authors ranged from $7.8 \mu \mathrm{g} / \mathrm{mL}$ to $500 \mu \mathrm{g} / \mathrm{mL}$. These authors reported that in this range of MIC values, the fractions exhibited higher microorganisms' inhibition than the extracts. Likewise, according to these authors, the Gram-positive pathogens showed higher sensitivity than the Gram-negative, due to the same reasons pointed previously. Comparing the results obtained in the present work with the previously mentioned ones, it can be observed that the values are significantly different. This may be due to the fact that in the work reported by other authors, a bioresidue of juice production from the pulp of red pitaya fruit was analysed, that can affect the concentration and composition of the compounds presented by fresh fruits in ideal consumption conditions.

Concerning the toxicity evaluation on normal cells PLP2 at a maximum of $400 \mu \mathrm{g} / \mathrm{mL}$, the extract did not reveal toxicity, demonstrating at a first screening that its use and application as a natural food colorant can be safe.

\subsection{Optimized extraction conditions for betalains}

Given the growing demand for natural ingredients to be used as food additives, such as colorants like betalains, new alternative plant matrices and technologies are being exploited by the scientific community and industry, with a focus on increasing the yield of betalains in a more efficient and sustainable way. Based on the knowledge previously established in the recovery of betacyanins from flowers of Gomphrena globosa L. using UAE (Roriz et al., 2017; Roriz, Barros, Prieto, Morales, \& Ferreira, 2017), and the information available in the literature for this class of compounds in this specific matrix (Bhagya Raj \& Dash, 2020; Ramli, Ismail, \& Rahmat, 2014), the suitability of this methodology was herein investigated in the recovery of this class of compounds from the $H$. constaricensis fruit peel. The choice of this methodology fell on the fact that the UAE technique is based on the principle of cell disruption, caused by acoustic cavitation, which affects and promotes mass transfer phenomena, thus increasing the extraction yield of target compounds quickly and efficiently (Pinela et al., 2019; Rocha et al., 2020). However, it is necessary to pay attention to the amount of applied energy, because when too much, it can compromise the integrity of the target molecules, as well as to the other factors used in the intensification of the extraction process. Therefore, and as a way to minimize these problems, relevant dependent variables must be combined in an experimental design applied with RSM, an optimization tool that allows to evaluate the interactions between the independent variables and to optimize the recovery of the compounds of interest, applying a reduced number of experimental runs (Roriz, Barros, Prieto, Barreiro, et al., 2017).

\subsubsection{Experimental data for RSM optimization}

The experimental results obtained with the 18 runs of the CCD design for the variables of time $(t)$ and ultrasonic power $(P)$ are shown in Table 5. For the extraction yield (extract weight), values ranging from 3.98 to $4.95 \%(w / w)$ were obtained. Phyllocactin was the major compound identified in red pitaya peel extract. The lowest levels of this compound $(6.31 \mathrm{mg} / \mathrm{g}$ of plant material) were quantified in run 1 , where the independent variables were combined at medium-low levels (-1); on the other hand, the higher content $(12.21 \mathrm{mg} / \mathrm{g}$ of plant material) was obtained in run 8 with the combination of the independent variables at medium-high $(+1)$ and medium (0) levels. The result observed in the first case is an indication that the intensity of the combined variables does not adequately promote the extraction, probably due to the reduced time and low ultrasonic power applied, unlike the application of both variables at high intensity that can lead to the pigment degradation. In the run displaying the best result, it is possible to observe that when long extraction times are applied, combined with medium 
Table 5

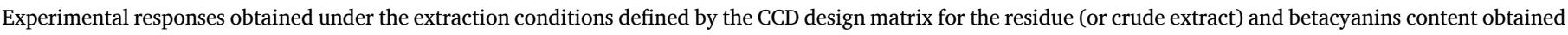
from red pitaya peel.

\begin{tabular}{|c|c|c|c|c|c|c|c|c|}
\hline \multirow[t]{2}{*}{ Runs } & \multicolumn{2}{|c|}{ Experimental domain } & \multicolumn{6}{|c|}{ Experimental responses } \\
\hline & Time (min) & Power (W) & Residue $(\%, w / w)$ & $\begin{array}{l}\text { Betanin* (mg/ } \\
\text { g) }\end{array}$ & $\begin{array}{l}\text { Isobetanin (mg/ } \\
\mathrm{g})\end{array}$ & $\begin{array}{l}\text { Phyllocactin (mg/ } \\
\text { g) }\end{array}$ & $\begin{array}{l}\text { Isophyllocactin (mg/ } \\
\mathrm{g})\end{array}$ & $\begin{array}{l}\text { Total betacyanins (mg/ } \\
\mathrm{g})\end{array}$ \\
\hline 1 & $-1(4.5)$ & $-1(44.4)$ & 4.12 & 6.99 & 7.22 & 6.31 & 5.87 & 26.38 \\
\hline 2 & $+1(41.5)$ & $-1(44.4)$ & 4.08 & 7.27 & 8.05 & 10.88 & 5.69 & 31.90 \\
\hline 3 & $-1(4.5)$ & $+1(460.6)$ & 4.13 & 7.52 & 8.81 & 12.01 & 8.26 & 36.60 \\
\hline 4 & $+1(41.5)$ & $+1(460.6)$ & 4.95 & 5.72 & 9.12 & 10.44 & 11.17 & 36.46 \\
\hline 5 & $-1.19(1)$ & $0(252.5)$ & 4.00 & 8.03 & 8.55 & 10.38 & 8.77 & 35.74 \\
\hline 6 & $-1.19(1)$ & $0(252.5)$ & 3.98 & 5.64 & 8.43 & 9.43 & 8.77 & 32.27 \\
\hline 7 & +1.19 (45) & $0(252.5)$ & 4.49 & 7.29 & 9.53 & 11.33 & 10.42 & 38.57 \\
\hline 8 & $+1.19(45)$ & $0(252.5)$ & 4.46 & 7.56 & 9.53 & 12.21 & 10.42 & 39.72 \\
\hline 9 & $0(23)$ & $-1.19(5)$ & 4.20 & 6.35 & 6.94 & 6.86 & 4.55 & 24.70 \\
\hline 10 & $0(23)$ & $-1.19(5)$ & 4.02 & 5.63 & 6.22 & 6.22 & 4.59 & 22.66 \\
\hline 11 & $0(23)$ & $+1.19(500)$ & 4.91 & 6.56 & 8.45 & 11.16 & 8.54 & 34.71 \\
\hline 12 & $0(23)$ & -1.19 (5) & 4.91 & 6.70 & 8.03 & 9.89 & 7.17 & 31.80 \\
\hline 13 & $0(23)$ & $0(252.5)$ & 4.45 & 6.78 & 8.59 & 9.49 & 6.94 & 31.80 \\
\hline 14 & $0(23)$ & $0(252.5)$ & 4.53 & 7.19 & 9.06 & 10.97 & 8.56 & 35.78 \\
\hline 15 & $0(23)$ & $0(252.5)$ & 4.46 & 6.80 & 8.90 & 10.61 & 8.08 & 34.39 \\
\hline 16 & $0(23)$ & $0(252.5)$ & 4.41 & 6.80 & 8.70 & 10.06 & 7.92 & 33.47 \\
\hline 17 & $0(23)$ & $0(252.5)$ & 4.34 & 7.41 & 8.13 & 10.00 & 7.79 & 33.34 \\
\hline 18 & $0(23)$ & $0(252.5)$ & 4.50 & 7.77 & 8.61 & 10.96 & 9.25 & 36.59 \\
\hline
\end{tabular}

*Response variable not optimized since no significant parametric values were found to construct a predictive model.

For betacyanins, the results are expressed in $\mathrm{mg} / \mathrm{g}$ of dry plant material (dw).

ultrasonic power values, a more efficient extraction of the compound was promoted, without causing its degradation. The same trend was observed for the sixth response variable (total betacyanins), resulting in the higher amount of the sum of all betacyanins $(39.72 \mathrm{mg} / \mathrm{g}$ of plant material) quantified in the aqueous peel extracts, were only the three major compounds were considered to perform the optimization procedure, where phyllocactin $(\sim 31 \%)$ presented itself as the major compound, followed by isophyllocactin $(\sim 26 \%)$, isobetanin $(\sim 24 \%)$, and finally betanin $(\sim 19 \%)$; this last one was not optimized since no significant parametric values were found for the construction of a predictive model.

\subsubsection{Analysis of the theoretical response surface models}

Using Design-Expert software, the response values presented in Table 5 were fitted to a polynomial regression model, but only the significant parameters (assessed at a 95\% confidence level) were used for the construction of the predictive models. The results of the ANOVA and regression analysis are shown in Table S2 (Supplementary material), and the constructed polynomial models, expresses in coded values, are presented in Equations (2)-(6).

$$
\begin{aligned}
& Y_{\text {Yield }}=4.47+0.2 t+0.2 P-0.16 t^{2}+0.22 t P \\
& Y_{\text {Isobetanin }}=8.6+0.37 t+0.68 P+0.3 t^{2}-0.8 P^{2} \\
& Y_{\text {Phylocactin }}=10.2+0.8 t+1.5 P+0.6 t^{2}-1.0 P^{2}-1.5 t P \\
& Y_{\text {Isophylocactin }}=7.9+0.7 t+1.6 P+1.2 t^{2}-1.2 P^{2}+0.8 t P \\
& Y_{\text {Totalbetacyanins }}=33.6+1.8 t+3.7 P+2.4 t^{2}-3.7 P^{2}
\end{aligned}
$$

For each response variable in the developed mathematical models, the coefficients illustrate de effect of the independent variables and their interactions. The expected effect on the response when changing one factor value is represented by the parametric values. So, a higher parametric value (regardless of the signal), means a more significant weight of the respective variable, while, for interactions, negative and positive signs means an antagonistic and synergistic effect, respectively, between variables (Rocha et al., 2020). The intercept, in each model equation, corresponds to the average response of the 18 runs of the CCD design (Table 5).

The polynomial model equations adequately describe the effects of the independent variables on the target responses, as demonstrated by the non-significant lack-of-fit $(p>0.05)$ and adequate precision $>15$ (see Table S2 of Supplementary material) (Iberahim, Sethupathi, Goh, Bashir, \& Ahmad, 2019). For Equations (2)-(6), the coefficients $\mathrm{R}^{2}$ and $\mathrm{R}^{2}$ adj were higher than 0.88 and 0.84 , respectively, showing that the variability of each response can be explained by the two independent variables involved in the extraction. As a measure of signal-to-noise ratio, the adequate precision presented values higher than 15 in all cases (Supplementary material Table S2). All this validated statistically the developed polynomial models to be used in the following steps to predict the optimal UAE conditions. Analysing Equations (2)-(6), it can be observed that both independent variables induced significant effects mainly through positive linear terms, while the quadratic terms were negative in some cases, especially for the variable ultrasonic power. Based on the dimension of the parametric values, it was also observed that the impact of the ultrasonic power was more pronounced than that of the processing time. For the interactive effects, only the major compound (phyllocactin) was impacted by a negative interaction between the independent variables. These results support the application of RSM as optimization tool, since the one-factor-at-a-time approaches do not evaluate interactive effects.

\subsubsection{Effect of the independent variables on the target responses}

Fig. 1 shows 3D response surface graphs generated to illustrate and make it easier to understand the effect of the independent variables on the extraction yield and betacyanin levels. It was possible to verify that, in general, an increase in the response values resulted from an increase in the processing time and application of a medium-high ultrasonic power. In the particular case of phyllocactin, it should be noted that there is not only a maximum response area, since the response was also maximized by the combination of high ultrasonic powers with reduced extraction times. In the different 3D graphs, it is possible to notice that low power sonication for shorter time periods is not enough to effectively promote the satisfactory recovery of the pigments. This effect was also particularly noted in the phyllocactin response surface graph, as also in the graph obtained for the residue (crude extract).

Overall, it was necessary to work close to the extreme conditions to recover considerable quantities of the pitaya peel pigments. However, as illustrated in Figure S1 (Supplementary material), ultrasonic powers above $\sim 370 \mathrm{~W}$ appeared to decrease the total betacyanin content, probably due to a negative impact of this variable. In fact, the 

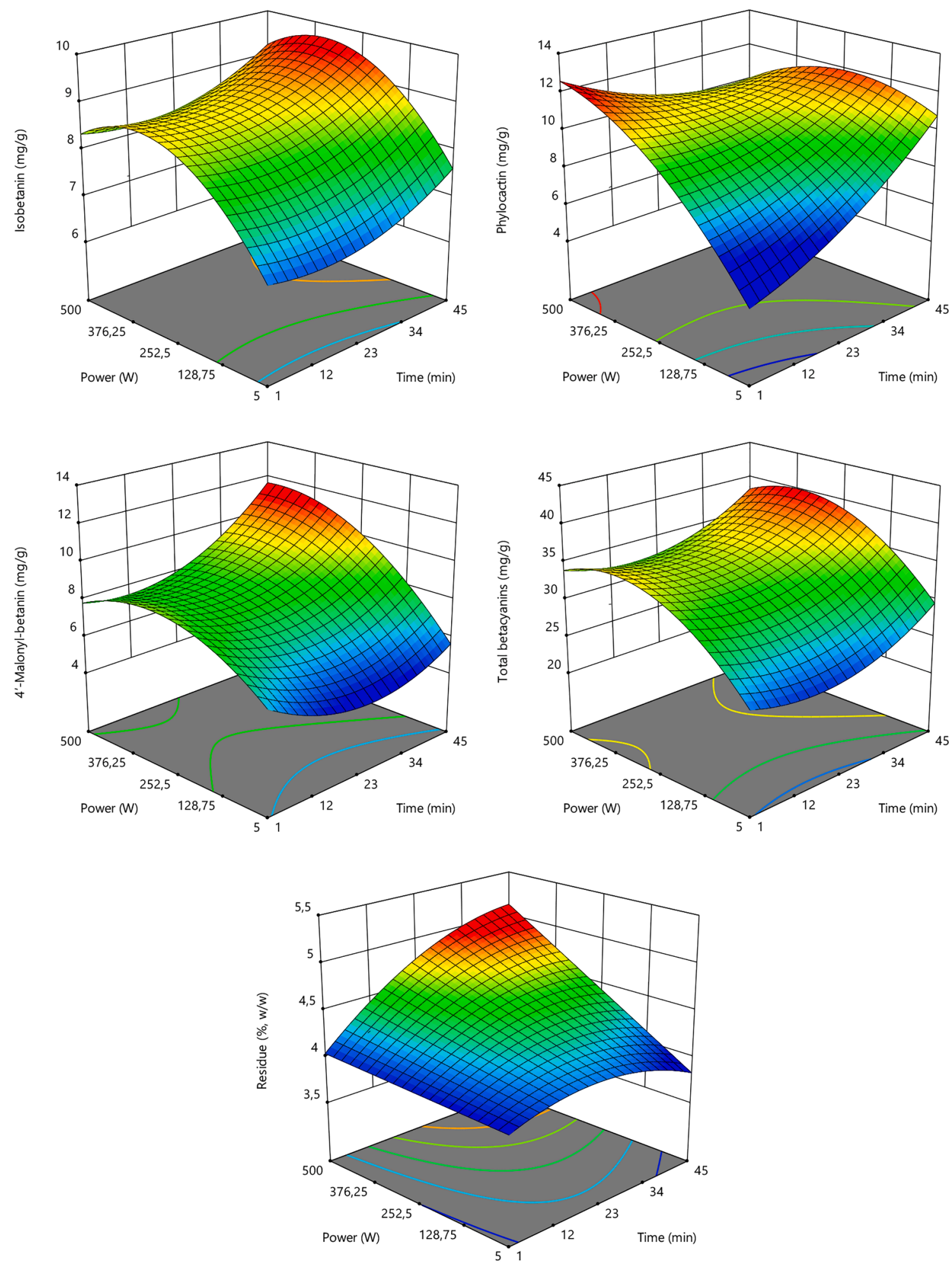

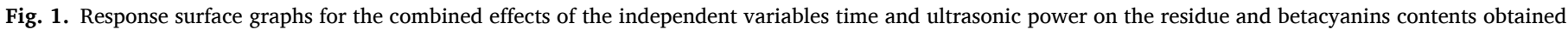
from red pitaya peel. (For interpretation of the references to colour in this figure legend, the reader is referred to the web version of this article.)

intensification factors must be applied in a sufficient intensity to promote the recovery of the pigments, but that do not compromise their integrity. There are some other factors that affect the stability of betacyanins, such as temperature, $\mathrm{pH}$, light intensity, presence of oxygen and enzymes, among others, as already described by some authors (Miguel, 2018). It is also known that betacyanins can isomerize, deglicozilate or decarboxylate when exposed to extreme processing conditions, as a function of their structural characteristics (Manchali, Chidambara Murthy, Nagaraju, \& Neelwarne, 2012).

\subsubsection{Optimal extraction conditions}

Table S3 (Supplementary material) presents the optimal extraction condition predicted with the theoretical model Equations (2)-(6) for each response variable, which can be summarized as follows: i) $5.70 \pm$ 
$0.06 \%$ extract weight $(w / w)$ are obtained when applied $500 \mathrm{~W}$ for 37 min to the extraction mixture; ii) $9.6 \pm 0.2 \mathrm{mg}$ of isobetanin/g of pant material are obtained when applied $337 \mathrm{~W}$ for $44 \mathrm{~min}$; iii) $11.9 \pm 0.3 \mathrm{mg}$ of phyllocactin/g of plant material are obtained when applied $229 \mathrm{~W}$ for $45 \mathrm{~min}$; iv) $11.4 \pm 0.4 \mathrm{mg}$ of isophyllocactin $/ \mathrm{g}$ of pant material are obtained when applied $377 \mathrm{w}$ for $45 \mathrm{~min}$; and v) $40 \pm 1 \mathrm{mg}$ of total betacyanins/g of pant material are obtained when applied $346 \mathrm{~W}$ for 34 $\mathrm{min}$. The recovery of total betacyanins and residue required almost the same interval of time, while total betacyanins required a lower ultrasonic power. Another determination that was made in this study, and which is also presented in Table S3 (Supplementary material), are the optimal extraction conditions that maximize both residue and total betacyanins contents, due to the importance to achieve a high extract weight with high levels of colouring compounds to be a suitable alternative to be used as a natural colorant for the industry. Therefore, based on the second optimization, it was concluded that $38 \mathrm{~min}$ sonication at $487 \mathrm{~W}$ were the optimal UAE conditions to maximize the response variables simultaneously as much as possible (5.05 $\pm 0.06 \%$ residue and $36 \pm 1 \mathrm{mg} / \mathrm{g}$ of total betacyanins).

In a previous study with globe amaranth flowers (Roriz et al., 2017), the optimal UAE conditions that maximize the aqueous extraction of betacyanins were characterized by $22 \mathrm{~min}$ sonication at $500 \mathrm{~W}(20 \mathrm{kHz})$. In this particular case, the longest time required to reach the optimal extraction conditions may have been caused by the intrinsic nature of the plant material and by different betacyanin compounds. For this fruit species in particular, UAE has been tested previously, but with the aim of recovery pectin from the fruit peel (Lin, Kai, \& Ali, 2018)Nguyen, Pirak, \& Yildiz, 2019; Thu Dao, Webb, \& Malherbe, 2021; Zaid et al., 2020). Regarding the extraction of betacyanins from this matrix using UAE, little has been done. Regarding previous studies on this methodology and class of compounds involving other natural sources, Melgar et al. (2019) and Ahmed et al. (2020) reported UAE as a time-saving method for extraction of betalains from prickly pear (Opuntia engelmannii Salm-Dyck ex Engelm.) peel (2.5 min processing at $2 \mathrm{kHz}$ and $200 \mathrm{rpm}$, using $34.6 \%$ methanol at $\mathrm{pH}$ 7) and red amaranth (Amaranthus cruentus L.) leafy part ( 5 min sonication at $35 \mathrm{kHz}$, using water at $70{ }^{\circ} \mathrm{C}$ ), respectively.

\section{Conclusion}

The chemical characterization and bioactive properties of red pitaya peel, a by-product of the pulp juice making industry, were evaluated in order to promote its valorisation. Additionally, an UAE process for the detected betacyanins was also optimized by RSM. Chromatographic analyses and bioactivity assays allowed to characterize the profile in organic acids, tocopherols, and betacyanins and assess its antioxidant and antimicrobial potential and safety issues. Although the main objective of this work was to obtain a colouring agent, it was relevant to characterize all these molecules, since there is little or no information about this plant matrix in the literature.

The red pitaya extract displayed antihaemolytic activity and antibacterial effects, with no hepatotoxicity to PLP2 cells. Given the wellknown colouring capacity of betacyanins, its UAE was optimized in order to obtain a betacyanin-rich extract. The two independent variables, extraction time and ultrasonic power, affected significantly the UAE process. The predictive models were successfully fitted to the experimental data and validated based on different statistical criteria. It was possible to achieve $5.05 \%$ of residue (or extract weight, $w / w$ ) and $36 \mathrm{mg} / \mathrm{g}$ of total betacyanins when operating at $487 \mathrm{~W}$ during $38 \mathrm{~min}$. This betacyanin-rich extract can be highlighted as a promising natural alternative to artificial food colorants, since in addition to providing a certain colour, it also has antioxidant and antibacterial effects of relevance for food preservation.

Overall, the acquired knowledge encourages the recycling of red pitaya peel as an alternative low-cost source of safe, health-promoting natural colorants for the food industry.

\section{Declaration of Competing Interest}

The authors declare that they have no known competing financial interests or personal relationships that could have appeared to influence the work reported in this paper.

\section{Acknowledgements}

The authors are grateful to the Foundation for Science and Technology (FCT, Portugal) for financial support by national funds FCT/ MCTES to CIMO (UIDB/00690/2020); C. L. Roriz PhD's grant (SFRH/ BD/117995/2016), L. Barros and C. Calhelha also thank the national funding by FCT, P.I., through the institutional scientific employment program-contract for their contracts, and S.A. Heleno (CEECIND/ 03040/2017) and J. Pinela (CEECIND/01011/2018) through the individual scientific employment program-contract. The authors are also grateful to the European Regional Development Fund (ERDF) through the Regional Operational Program North 2020, within the scope of project Mobilizador Norte-01-0247-FEDER-024479: ValorNatural $\AA$ and GreenHealth (Norte-01-0145-FEDER-000042. Finally, P. Morales is also grateful to UCM ALIMNOVA Research Group (GR105/18).

\section{Appendix A. Supplementary data}

Supplementary data to this article can be found online at https://doi. org/10.1016/j.foodchem.2021.131344.

\section{References}

Ahmed, M., Ramachandraiah, K., Jiang, G.-H., \& Eun, J. B. (2020). Effects of ultrasonication and agitation on bioactive compounds and structure of amaranth extract. Foods, 9(8), 1116.

Albuquerque, B. R., Pinela, J., Barros, L., Oliveira, M. B. P. P., \& Ferreira, I. C. F. R. (2020). Anthocyanin-rich extract of jabuticaba epicarp as a natural colorant: Optimization of heat- and ultrasound-assisted extractions and application in a bakery product. Food Chemistry, 316, 126364. https://doi.org/10.1016/j. foodchem.2020.126364

Bakar, J., Ee, S. C., Muhammad, K., Hashim, D. M., \& Adzahan, N. (2013). Spray-drying optimization for red pitaya peel (Hylocereus polyrhizus). Food and Bioprocess Technology, 6(5), 1332-1342. https://doi.org/10.1007/s11947-012-0842-5

Barros, L., Pereira, E., Calhelha, R. C., Dueñas, M., Carvalho, A. M., Santos-Buelga, C., \& Ferreira, I. C. F. R. (2013). Bioactivity and chemical characterization in hydrophilic and lipophilic compounds of Chenopodium ambrosioides L. Journal of Functional Foods, 5(4), 1732-1740. https://doi.org/10.1016/j.jff.2013.07.019

Bhagya Raj, G. V. S., \& Dash, K. K (2020). Ultrasound-assisted extraction of phytocompounds from dragon fruit peel: Optimization, kinetics and thermodynamic studies. Ultrasonics Sonochemistry, 68. https://doi.org/10.1016/j. ultsonch.2020.105180

Cai, Y. Z., Xing, J., Sun, M., \& Corke, H. (2006). Rapid identification of betacyanins from Amaranthus tricolor, Gomphrena globosa, and Hylocereus polyrhizus by matrix-assisted laser desorption/ ionization quadrupole ion trap time-of-flight mass spectrometry (MALDI-QIT-TOF MS). Journal of Agricultural and Food Chemistry, 54(18), 6520-6526. https://doi.org/10.1021/jf0609983

de Mello, F. R., Bernardo, C., Dias, C. O., Gonzaga, L., Amante, E. R., Fett, R., \& Candido, L. M. B. (2015). Antioxidant properties, quantification and stability of betalains from pitaya (Hylocereus undatus) peel. Ciencia Rural, 45(2), 323-328. https://doi.org/10.1590/0103-8478cr20140548

Esquivel, P., Stintzing, F. C., \& Carle, R. (2007). Phenolic compound profiles and their corresponding antioxidant capacity of purple pitaya (Hylocereus sp.) genotypes. Zeitschrift Fur Naturforschung - Section C. Journal of Biosciences, 62(9-10), 636-644. https://doi.org/10.1515/znc-2007-9-1003

Faridah, A., Holinesti, R., \& Syukri, D. (2015). Betalains from Red Pitaya Peel (Hylocereus polyrhizus): Extraction, spectrophotometric and HPLC-DAD identification, bioactivity and toxicity screening. Pakistan Journal of Nutrition, 14(12), 976-982. https://doi. org/10.3923/pjn.2015.976.982

Guimarães, R., Barros, L., Dueñas, M., Calhelha, R. C., Carvalho, A. M., Santos-Buelga, C., ... Ferreira, I. C. F. R. (2013). Nutrients, phytochemicals and bioactivity of wild Roman chamomile: A comparison between the herb and its preparations. Food Chemistry, 136(2), 718-725. https://doi.org/10.1016/j.foodchem.2012.08.025

Hua, Q., Chen, C., Tel Zur, N., Wang, H., Wu, J., Chen, J., ... Qin, Y. (2018). Metabolomic characterization of pitaya fruit from three red-skinned cultivars with different pulp colors. Plant Physiology and Biochemistry, 126, 117-125. https://doi.org/10.1016/j. plaphy.2018.02.027

Iberahim, N., Sethupathi, S., Goh, C. L., Bashir, M. J. K., \& Ahmad, W. (2019). Optimization of activated palm oil sludge biochar preparation for sulphur dioxide adsorption. Journal of Environmental Management, 248, 109302. https://doi.org/ 10.1016/j.jenvman.2019.109302 
Jamilah, B., Shu, C. E., Kharidah, M., Dzulkifly, M. A., \& Noranizan, A. (2011). Physicochemical characteristics of red pitaya (Hylocereus polyrhizus) peel. 18 International Food Research Journal \$.

Lee, S., Suh, D. H., Lee, S., Heo, D. Y., Kim, Y. S., Cho, S. K., \& Lee, C. H. (2014). Metabolite profiling of red and white pitayas (Hylocereus polyrhizus and Hylocereus undatus) for comparing betalain biosynthesis and antioxidant activity. Journal of Agricultural and Food Chemistry, 62(34), 8764-8771. https://doi.org/10.1021/ jf5020704

Lim, H. K., Tan, C. P., Karim, R., Ariffin, A. A., \& Bakar, J. (2010). Chemical composition and DSC thermal properties of two species of Hylocereus cacti seed oil: Hylocereus undatus and Hylocereus polyrhizus. Food Chemistry, 119(4), 1326-1331. https://doi. org/10.1016/j.foodchem.2009.09.002

Lin, C. B., Kai, N. Y., \& Ali, A. (2018). Ultrasound assisted extraction of pectin from dragon fruit peels. Journal of Engineering Science and Technology, (Special Issue on the seventh eureea 2016), 65-81.

Lira, S. M., Dionísio, A. P., Holanda, M. O., Marques, C. G., da Silva, G. S., Correa, L. C., .. Zocolo, G. J. (2020). Metabolic profile of pitaya (Hylocereus polyrhizus (F.A.C. Weber) Britton \& Rose) by UPLC-QTOF-MSE and assessment of its toxicity and anxiolytic-like effect in adult zebrafish. Food Research International, 127(May, 2019). https://doi.org/10.1016/j.foodres.2019.108701

Manchali, S., Chidambara Murthy, K. N., Nagaraju, S., \& Neelwarne, B. (2012). Stability of betalain pigments of red beet. In B. Neelwarne (Ed.), Red Beet Biotechnology: Food and Pharmaceutical Applications (pp. 55-74). Springer US.

Mandim, F., Barros, L., Calhelha, R. C., Abreu, R. M. V., Pinela, J., Alves, M. J., Ferreira, I. C. F. R. (2019). Calluna vulgaris (L.) Hull: Chemical characterization, evaluation of its bioactive properties and effect on the vaginal microbiota. Food \& Function, 10(1), 78-89.

Martins, N., Roriz, C. L., Morales, P., Barros, L., \& Ferreira, I. C. F. R. (2016). Food colorants: Challenges, opportunities and current desires of agro-industries to ensure consumer expectations and regulatory practices. Trends in Food Science and Technology, 52, 1-15. https://doi.org/10.1016/j.tifs.2016.03.009

Martins, N., Roriz, C. L., Morales, P., Barros, L., \& Ferreira, I. C. F. R. (2017). Coloring attributes of betalains: A key emphasis on stability and future applications. Food and Function, 8(4), 1357-1372. https://doi.org/10.1039/c7fo00144d

Melgar, B., Dias, M. I., Barros, L., Ferreira, I. C. F. R., Rodriguez-Lopez, A. D., \& GarciaCastello, E. M. (2019). Ultrasound and microwave assisted extraction of Opuntia fruit peels biocompounds: Optimization and comparison using RSM-CCD. Molecules, 24(19), 3618. https://doi.org/10.3390/molecules 24193618

Miguel, M. G. (2018). Betalains in some species of the Amaranthaceae family: A review. Antioxidants, 7, 53. https://doi.org/10.3390/antiox7040053

Naderi, N., Stintzing, F. C., Ghazali, H. M., Manap, Y. A., \& Jazayeri, S. D. (2010). Betalain extraction from Hylocereus polyrhizus for natural food coloring purposes. Journal of the Professional Association for Cactus Development, 12, 143-154.

Nguyen, B. M. N., Pirak, T., \& Yildiz, F. (2019). Physicochemical properties and antioxidant activities of white dragon fruit peel pectin extracted with conventional and ultrasound-assisted extraction. Cogent Food \& Agriculture, 5(1), 1633076. https://doi.org/10.1080/23311932.2019.1633076

Nomura, K., Ide, M., \& Yonemoto, Y. (2005). Changes in sugars and acids in pitaya (Hylocereus undatus) fruit during development. Journal of Horticultural Science and Biotechnology, 80(6), 711-715. https://doi.org/10.1080/14620316.2005.11512003

Pereira, C., Barros, L., Carvalho, A. M., \& Ferreira, I. C. F. R. (2013). Use of UFLC-PDA for the analysis of organic acids in thirty-five species of food and medicinal plants. Food Analytical Methods, 6(5), 1337-1344. https://doi.org/10.1007/s12161-012-9548-6

Pinela, J., Prieto, M. A., Pereira, E., Jabeur, I., Barreiro, M. F., Barros, L., \& Ferreira, I. C. F. R. (2019). Optimization of heat- and ultrasound-assisted extraction of anthocyanins from Hibiscus sabdariffa calyces for natural food colorants. Food Chemistry, 275, 309-321. https://doi.org/10.1016/j.foodchem.2018.09.118

Pires, T. C. S. P., Dias, M. I., Barros, L., Alves, M. J., Oliveira, M. B. P. P., SantosBuelga, C., \& Ferreira, I. C. F. R. (2018). Antioxidant and antimicrobial properties of dried Portuguese apple variety (Malus domestica Borkh. cv Bravo de Esmolfe). Food Chemistry, 240, 701-706. https://doi.org/10.1016/j.foodchem.2017.08.010

Ramli, N. S., Ismail, P., \& Rahmat, A. (2014). Influence of conventional and ultrasonicassisted extraction on phenolic contents, betacyanin contents, and antioxidant capacity of red dragon fruit (Hylocereus polyrhizus). Scientific World Journal. https://doi.org/10.1155/2014/964731

Rebeca, O. P. S., Boyce, A. N., \& Chandran, S. (2010). Pigment identification and antioxidant properties of red dragon fruit (Hylocereus polyrhizus). African Journal of Biotechnology, 9(10), 1450-1454. https://doi.org/10.5897/ajb09.1603

Rocha, R., Pinela, J., Abreu, R. M. V., Añibarro-Ortega, M., Pires, T. C. S. P., Saldanha, A. L., ... Barros, L. (2020). Extraction of anthocyanins from red raspberry for natural food colorants development: Processes optimization and in vitro bioactivity. Processes, 8(11), 1447. https://doi.org/10.3390/pr8111447

Roriz, C. L., Barros, L., Prieto, M. A., Barreiro, M. F., Morales, P., \& Ferreira, I. C. F. R. (2017). Modern extraction techniques optimized to extract betacyanins from Gomphrena globosa L. Industrial Crops and Products, 105(April), 29-40. https://doi. org/10.1016/j.indcrop.2017.05.008

Roriz, C. L., Barros, L., Prieto, M. A., Círić, A., Soković, M., Morales, P., \& Ferreira, I. C. F. R. (2018). Enhancing the antimicrobial and antifungal activities of a coloring extract agent rich in betacyanins obtained from: Gomphrena globosa L. flowers. Food and Function, 9(12), 6205-6217. https://doi.org/10.1039/c8fo01829d

Roriz, C. L., Barros, L., Prieto, M. A., Morales, P., \& Ferreira, I. C. F. R. (2017). Floral parts of Gomphrena globosa L. as a novel alternative source of betacyanins: Optimization of the extraction using response surface methodology. Food Chemistry, 229, 223-234. https://doi.org/10.1016/j.foodchem.2017.02.073

Roriz, C. L., Heleno, S. A., Carocho, M., Rodrigues, P., Pinela, J., Dias, M. I., .. Ferreira, I. C. F. R. (2020). Betacyanins from Gomphrena globosa L. flowers: Incorporation in cookies as natural colouring agents. Food Chemistry, 329, 127178. https://doi.org/10.1016/j.foodchem.2020.127178

Singh, K. P. (1997). Medicinal properties of mulberry : A review. Indian Drugs, 34(9), 488-492.

Stintzing, F. C., Schieber, A., \& Carle, R. (2002). Betacyanins in fruits from red-purple pitaya, Hylocereus polyrhizus (Weber) Britton \& Rose. Food Chemistry, 77(1), 101-106. https://doi.org/10.1016/S0308-8146(01)00374-0

Taira, J., Tsuchida, E., Katoh, M. C., Uehara, M., \& Ogi, T. (2015). Antioxidant capacity of betacyanins as radical scavengers for peroxyl radical and nitric oxide. Food Chemistry, 166, 531-536. https://doi.org/10.1016/j.foodchem.2014.05.102

Tenore, G. C., Novellino, E., \& Basile, A. (2012). Nutraceutical potential and antioxidant benefits of red pitaya (Hylocereus polyrhizus) extracts. Journal of Functional Foods, 4 (1), 129-136. https://doi.org/10.1016/j.jff.2011.09.003

Thu Dao, T. A., Webb, H. K., \& Malherbe, F. (2021). Optimization of pectin extraction from fruit peels by response surface method: Conventional versus microwaveassisted heating. Food Hydrocolloids, 113, 106475. https://doi.org/10.1016/j. foodhyd.2020.106475

Volpentesta, A. P., Felicetti, A. M., \& Ammirato, S. (2017). Intelligent food information provision to consumers in an internet of food era. IFIP Advances in Information and Communication Technology, 506, 725-736. https://doi.org/10.1007/978-3-31965151-4_65

Yong, Y. Y., Dykes, G., Lee, S. M., \& Choo, W. S. (2018). Effect of refrigerated storage on betacyanin composition, antibacterial activity of red pitahaya (Hylocereus polyrhizus) and cytotoxicity evaluation of betacyanin rich extract on normal human cell lines. LWT - Food Science and Technology, 91, 491-497. https://doi.org/10.1016/j. lwt.2018.01.078

Zaid, R. M., Mishra, P., Siti Noredyani, A. R., Tabassum, S., Ab Wahid, Z., \& Mimi Sakinah, A. M. (2020). Proximate characteristics and statistical optimization of ultrasound-assisted extraction of high-methoxyl-pectin from Hylocereus polyrhizus peels. Food and Bioproducts Processing, 123, 134-149. https://doi.org/10.1016/j. fbp.2020.06.011 